Jurnal Dinamika Sosial Ekonomi Vol.21 No.2, Desember 2020 : 122-136

ISSN 1411-593X (print); ISSN 2721-3137 (online)

\title{
ANALISIS TINGKAT KETAHANAN PANGAN RUMAH TANGGA BERDASARKAN KLASIFIKASI SILANG PANGSA PENGELUARAN PANGAN DAN KECUKUPAN ENERGI DI KECAMATAN SAMPANG, KABUPATEN CILACAP, PROVINSI JAWA TENGAH
}

\author{
Analysis of Household Food Security Based On Cross Classification of Food \\ Expenditure and Energy Adequacy at Sampang Sub-District, Cilacap Regency, Central \\ Java \\ Miouke Kezia, Nanik Dara Senjawati, Indah Widowati \\ Program Studi Agribisnis Jurusan Agribisnis Fakultas Pertanian \\ Universitas Pembangunan Nasional Veteran Yogyakarta \\ J1. SWK 104 (Lingkar Utara) Codong Catur Yogyakarta \\ Indonesia 55283 \\ *email korespondensi: mioukekezia30@gmail.com
}

Diterima tanggal : 11 Agustus 2020 ; Disetujui tanggal : 22 Agustus 2020

\begin{abstract}
This research aimed (1) to analyze the level of household food security based on cross classification of food expenditure and sufficiency of energy then (2) to analyzed the diversification level of household food consumed at Sampang Sub-district, Cilacap Regency based on PPH score calculation. This research determined to analysis descriptive, the method of conducting research using survey methods. The method of determining the location is multistage random sampling. For sampling using simplerandom sampling method to select 44 households to be sampled in Karangtengah Village to represent the Sampang Sub-District. To collect data the method used are interview observation, and recording family food consumption for 24 hours. Analysis of food expenditure calculated by using ratio distribution of food expenditure and total household expenditure, energy adequacy is calculated by using ratio distribution of total energy consumption and total of household energi adequacy. This research resulted indicated that (1) the level of household food security at Sampang Sub-district Cilacap Regency in a food vulnerable state base on cross classification of food expenditure and sufficiency of energy then (2) the level of household food consumption diversification based calculation PPH score of 89.6, so it belongs to the golden triangle category.
\end{abstract}

Keywords : Energy Adequacy, Food Consuming Diversification, Food Expenditure, , Household Food Security 
Jurnal Dinamika Sosisal Ekonomi, 21 (2) : 122-136

\begin{abstract}
ABSTRAK
Tujuan penelitian ini adalah (1) menganalisis tingkat ketahanan pangan rumah tangga yang diukur dengan klasifikasi silang pangsa pengeluaran pangan dan angka kecukupan energi serta (2) menganalisis tingkat diversifikasi pangan rumah tangga berdasarkan perhitungan skor PPH di Kecamatan Sampang, Kabupaten Cilacap. Metode dasar yang digunakan adalah metode deskriptif analitis, metode pelaksanaan peneletian survei, metode penentuan lokasi adalah multistage random sampling. Pengambilan sampel menggunakan simple random sampling untuk memilih 44 rumah tangga di Desa Karangtengah yang akan dijadikan sampel untuk mewakili Kecamatan Sampang. Untuk pengumpulan data dilakukan melalui observasi wawancara, pencatatan konsumsi pangan yang menggunakan metode Food Recall 24 jam. Analisis pangsa pengeluaran pangan diperoleh dari pengeluaran pangan terhadap pengeluaran total rumah tangga dengan uji one sample t-test, dan kecukupan energi diperoleh dari total konsumsi energi terhadap total angka kecukupan energi rumah tangga dengan uji one sample t-test. Hasil penelitian menunjukkan bahwa (1) tingkat ketahanan pangan rumah tangga di Kecamatan Sampang Kabupaten Cilacap berdasarkan klasifikasi silang pangsa pengeluaran pangan dan kecukupan energi termasuk ke dalam kategori rentan pangan dan (2) tingkat diversikasi konsumsi pangan berdasarkan perhitungan skor PPH adalah sebesar 89,6 sehingga masuk ke dalam kategori segitiga emas.
\end{abstract}

Kata Kunci:Ketahanan Pangan Rumah Tangga, Pangsa Pengeluaran Pangan, dan Angka Kecukupan Energi. Diversifikasi Konsumsi Pangan.

\title{
PENDAHULUAN
}

Undang-Undang No. 18 Tahun 2012 tentang pangan mengamanatkan bahwa penyelenggaraan pangan dilaksanakan untuk memenuhi kebutuhan dasar manusia yang memberikan manfaat secara adil, merata, dan berkelanjutan berdasarkan kedaulatan pangan, kemandirian pangan dan ketahanan pangan. Sistem ketahanan pangan di Indonesia secara komprehensif meliputi empat subsistem, yaitu: 1) Ketersediaan pangan dalam jumlah dan jenis yang cukup untuk seluruh penduduk, 2) Distribusi pangan yang lancar dan merata, 3) Konsumsi pangan setiap individu yang memenuhi kecukupan gizi seimbang, yang berdampak pada, 4) Status gizi masyarakat. Ketahanan pangan terwujud apabila secara umum telah terpenuhi dua aspek sekaligus. Pertama adalah tersedianya pangan yang cukup dan merata untuk seluruh penduduk. Kedua, setiap penduduk mempunyai 
akses fisik dan ekonomi terhadap pangan untuk memenuhi kecukupan gizi guna menjalani kehidupan yang sehat dan produktif dari hari ke hari (Dewan Ketahanan Pangan, 2006). Menurut Usfar (2002) dalam Suharyanto (2015) ketahanan pangan rumah tangga berhubungan dengan kemampuan rumah tangga tersebut untuk memenuhi kebutuhan seluruh anggotanya. Hal ini menyiratkan akses fisik dan ekonomi terhadap pangan yang cukup dalam kuantitas dan kualitas gizi, aman, dan dapat diterima oleh budaya setempat untuk memenuhi kebutuhan tiap anggota keluarga. Akses rumah tangga terhadap pangan merupakan strategi-strategi untuk mendapatkan makanan dari berbagai sumber.

Terdapat banyak indikator yang digunakan untuk mengukur ketahanan pangan rumah tangga. Penelitian Jonsson dan Toole (1991) dalam Dirhamsyah (2016) mengukur ketahanan pangan dengan klasifikasi silang antara proporsi pengeluaran pangan dan konsumsi gizi rumah tangga. Semakin besar proporsi pengeluaran rumah tangga untuk bahan pangan, maka akses terhadap bahan pangan adalah rendah sedangkan semakin kecil proporsi pengeluaran rumah tangga untuk bahan pangan, maka akses terhadap bahan pangan adalah besar, atau menunjukkan semakin tinggi ketahanan pangannya (Purwaningsih, 2008). Penelitian Anggraini (2014) menyatakan bahwa daerah penelitian yang didominasi oleh rumah tangga rentan pangan menunjukkan proporsi pengeluaran pangan yang tinggi namun cukup mengkonsumsi energinya. Hal ini dikarenakan adanya kesulitan-kesulitan dalam menjangkau pangan seperti pendapatan yang rendah dan distribusi pangan yang belum berjalan dengan baik. Hal tersebut dapat terjadi, dikarenakan sebagian besar rumah tangga responden mengkonsumsi jenis bahan pangan sumber karbohidrat tinggi seperti beras dan pangan murah untuk mengatasi rasa lapar.

Kecamatan Sampang merupakan satu dari 24 kecamatan yang berada di Kabupaten Cilacap. Kecamatan Sampang memiliki luas wilayah sebesar 27,3 km2 dengan jumlah penduduk pada tahun 2017 sebanyak 37.855 jiwa dengan jumlah rumah tangga 12.930 (Badan Pusat Statistik Kabupaten Cilacap, 2018). Pada tahun 
Jurnal Dinamika Sosisal Ekonomi, 21 (2) : 122-136

2017 sebanyak 10.116 mata pencaharian penduduk di Kecamatan Sampang masih didominasi sebagai buruh tani. Buruh tani merupakan pekerja serabutan yang hanya bekerja pada saat-saat tertentu saja ketika mendapat panggilan dan upah yang diterima sebagai pekerja buruh tani juga termasuk ke dalam upah yang sangat minim bahkan dibawah Upah Minimum Regional (UMR) Kabupaten Cilacap pada saat itu.

Melihat kondisi perekonomian sebagian besar penduduk di Kecamatan Sampang yang bekerja sebagai buruh tani memungkinkan bahwa pendapatan yang diterima untuk memenuhi kebutuhan rumah tangga masih sangat minim, akibat dari pendapatan yang minim maka pengeluaran pangan rumah tangga akan mengambil andil lebih besar daripada pengeluaran non pangan sehingga terdapat kemungkinan bahwa pangsa pengeluaran pangan rumah tangga tinggi. Karena pangsa pengeluaran pangan yang tinggi maka memungkinkan pula kecukupan energi rumah tangga dalam kategori cukup, karena sebagian besar pendapatan dibelanjakan untuk memenuhi kebutuhan konsumsi. Berdasarkan informasi dan permasalahan tersebut, penelitian ini difokuskan untuk menganalisis tingkat ketahanan pangan rumah tangga di Kecamatan Sampang Kabupaten Cilacap. Indikator yang digunakan dalam menganalisis ketahanan pangan rumah tangga di Kecamatann Sampang adalah klasifikasi silang pangsa pengeluaran pangan dan kecukupan energi.

\section{METODE PENELITIAN}

Penelitian ini dilaksanakan dengan metode survei, yaitu penelitian yang berkenaan dengan penyelidikan yang diadakan untuk memperoleh fakta-fakta dari gejala-gejala yang ada dan mencari keterangan-keterangan secara faktual. Penyelidikan dilakukan dalam waktu yang bersamaan terhadapap jumlah individu atau unit, baik secara sensus atau dengan menggunakan sampel (Nazir, 2014). Metode penentuan lokasi penelitian yang dilakukan menggunakan metode acak bertingkat (multistage random sampling), yaitu penarikan sampel dilakukan dalam beberapa 
tahap sampai tahap dimana diperoleh gugus (cluster) yang homogen sehingga diperoleh Desa Karangtengah untuk mewakili pengambilan sampel di Kecamatan Sampang. Responden dalam penelitian ini adalah sampel dari populasi rumah tangga di Desa Karangtengah, Kecamatan Sampang, Kabupaten Cilacap yang ditentukan dengan teknik penentuan sampel secara acak (simple random sampling), yaitu pengambilan responden dari populasi dilakukan secara acak tanpa memperhatikan strata yang ada di dalam populasi (Sugiyono, 2016). Dalam penelitian ini pengambilan sampel dilakukan pada 44 rumah tangga yang berada di Desa Karangatengah untuk mewakili pengambilan sampel yang dilakukan di Kecamatan Sampang.

\section{Analisis Tingkat Ketahanan Pangan Rumah Tangga}

Menurut penelitian Jonsson dan Toole (1991), untuk mengukur tingkat ketahanan pangan rumah tangga digunakan klasifikasi silang dua indikator pangsa pengeluaran pangan dan kecukupan energi. Derajat ketahanan pangan rumah tangga dapat dilihat pada Tabel 1 berikut:

Tabel 1. Derajat Ketahana Pangan Rumah Tangga

\begin{tabular}{|c|c|c|}
\hline \multirow[b]{2}{*}{$\begin{array}{l}\text { Konsumi Energi per unit } \\
\text { ekuivalen dewasa }\end{array}$} & \multicolumn{2}{|c|}{ Pangsa Pengeluaran Pangan } \\
\hline & $\begin{array}{c}\text { Rendah } \\
(<60 \% \text { pengeluaran } \\
\text { total })\end{array}$ & $\begin{array}{c}\text { Tinggi } \\
(\geq 60 \% \text { pengeluaran } \\
\text { total })\end{array}$ \\
\hline $\begin{array}{c}\text { Cukup } \\
\text { (>80\% kecukupan energi) }\end{array}$ & Tahan pangan & Rentan pangan \\
\hline $\begin{array}{c}\text { Kurang } \\
(\leq 80 \% \text { kecukupan energi) }\end{array}$ & Kurang pangan & Rawan pangan \\
\hline
\end{tabular}

Sumber: Jonsson dan Toole, 1991 dalam Dirhamsyah, 2016

Rumah tangga yang memiliki pangsa pengeluaran pangan kurang dari 60 persen dan kecukupan energi lebih besar dari 80 persen dikategorikan tahan pangan. Jika pangsa pengeluaran pangan lebih dari 60 persen dan kecukupan energi lebih dari 80 persen dikategorikan rentan pangan. Jika pangsa pengeluaran pangan kurang dari 60 persen dan kecukupan energi kurang dari 80 persen dikategorikan dikategorikan 
Jurnal Dinamika Sosisal Ekonomi, 21 (2) : 122-136

kurang pangan. Sedangkan apabila pangsa pengeluaran pangan lebih dari 60 persen dan kecukupan energi kurang dari 80 persen dikategorikan rawan pangan.

\section{Analisis Pangsa Pengeluaran Pangan}

Menurut Yudaningrum (2011) dalam Arida et. al., (2015), memaparkan perhitungan pangsa pengeluaran pangan terhadap pengeluaran total rumah tangga yang dapat dihitung dengan menggunakan rumus sebagai berikut :

$$
\mathrm{PPP}=
$$

Keterangan :

$\mathrm{PPP}=$ pangsa pengeluaran pangan $(\%)$

$\mathrm{PP} \quad=$ pengeluaran pangan $(\mathrm{Rp} /$ bulan $)$

$\mathrm{TP}=$ total pengeluaran rumah tangga $(\mathrm{Rp} / \mathrm{bulan})$

\section{Analisis Kecukupan Energi}

Pengukuran kecukupan energi dengan cara menghitung banyaknya konsumsi tiap rumah tangga. Metode analisis data ini bertujuan untuk mengukur tingkat ketahanan pangan rumah tangga menggunakan pendekatan Tingkat Konsumsi Energi (TKE). Pengukuran tingkat konsumsi energi adalah sebagai berikut:

$$
T K E=\frac{\sum \text { Konsums } i \text { Energi }}{\sum A K E \text { yang dianjurkan }} \times 100 \%
$$

Keterangan :

TKE = Tingkat Konsumsi Energi Rumah Tangga (\%)

$\sum \mathrm{AKE}=$ Jumlah konsumsi energi rumah tangga (Kkal)

AKE yang digunakan pada penelitian ini merupakan syarat kecukupan energi berdasarkan umur dan jenis kelamin sesuai dengan Peraturan Menteri Kesehatan Republik Indonesia No. 75 Tahun 2013 Tentang Angka Kecukupan Gizi Yang Dianjurkan Bagi Bangsa Indonesia.

\section{Analisis Diversifikasi Konsumsi Pangan Rumah Tangga}

Tingkat diversifikasi konsumsi pangan rumah tangga dapat diukur mealui pendekatan skor pola pangan harapan konsumsi atau PPH konsumsi. Langkahlangkah dalam penghitungan skor dan komposisi PPH konsumsi dalam buku panduan perhitungan pola pangan harapan (PPH) (2015) adalah sebagai berikut: 
Kezia et.al. Analisis Tingkat Ketahanan Pangan Rumah Tangga Berdasarkan

Pengelompokkan Pangan

Pangan yang dikonsumsi dikelompokkan menjadi 9 (sembilan) kelompok pangan yang mengacu pada standar Pola Pangan Harapan (PPH), seperti pada Tabel 2 berikut:

Tabel 2. Pengelompokkan Pangan

\begin{tabular}{ll}
\hline \multicolumn{1}{c}{ Kelompok Pangan } & \multicolumn{1}{c}{ Jenis Komoditas (Kelompok PPH) } \\
\hline Padi-padian & $\begin{array}{l}\text { Beras dan olahannya, jagung dan olahannya, } \\
\text { gandum dan olahannya. }\end{array}$ \\
Umbi-umbian & Ubi kayu dan olahannya, ubi jalar, kentang, talas, \\
dan sagu (termasuk makanan berpati). & Daging dan olahannya, ikan dan olahannya, telur, \\
Pangan hewani & serta susu dan olahannya. \\
Minyak dan lemak & Minyak kelapa, minyak sawit, margarin, dan lemak \\
& Kewani. \\
Buah atau biji berminyak & Kacang tanah, kacang kedelai, kacang hijau, kacang \\
Kacang-kacangan & merah, kacang polong, kacang mete, kacang \\
& tunggak, tahu, tempe, tauco, oncom, sari kedelai, \\
dan kecap. & Gula pasir, gula merah, sirup, minuman jadi dalam \\
botol/kaleng. & Sayur segar dan olahannya, buah segar dan \\
olahannya. & Aneka bumbu dan bahan minuman seperti terasi, \\
Gula & cengkeh, ketumbar, merica, pala, asam, bumbu \\
masak, teh, dan kopi.
\end{tabular}

Sumber : Badan Ketahanan Pangan, 2015

Konversi Bentuk, Jenis, dan Satuan

Melakukan konversi berat setiap jenis pangan dari URT (ukuran rumah tangga) menjadi gram.

Menghitung Sub Total Kandungan Energi Menurut Kelompok Pangan

Penghitungan kandungan energi setiap jenis pangan yang dikonsumsi dengan bantuan daftar komposisi bahan makanan (DKBM).

Menghitung Total Energi Aktual Seluruh Kelompok Pangan 
Jurnal Dinamika Sosisal Ekonomi, 21 (2) : 122-136

Total energi dari 9 kelompok pangan $=$ Energi kelompok padi-padian + umbiumbian + pangan hewani + minyak dan lemak + buah/biji berminyak + kacang kacangan + gula + sayur dan buah + energi kelompok lain-lain.

Menghitung Kontribusi Energi Dari Setiap Kelompok Pangan Terhadap Total Energi Aktual (\%)

Menghitung Kontribusi Energi Setiap Kelompok Pangan Terhadap Angka Kecukupan Energi (\%AKE)

$\frac{\text { Energikelompokpangan }}{\text { AKE konsums } i} \times 100 \%$

Menghitung Skor Aktual

Skor actual = kontribusi energi aktual setiap kelompok pangan $x$ bobot setiap kelompok pangan

Menghitung Skor AKE

Skor $A K E=\%$ AKE setiap kelompok pangan $x$ bobot

\section{Menghitung Skor PPH}

- Jika skor AKE lebih tinggi dari skor maksimum, maka yang digunakan adalah skor maksimum.

- Jika skor AKE lebih rendah dari skor maksimum, maka yang digunakan adalah skor AKE.

\section{Menghitung Total Skor PPH}

Skor PPH $=$ skor PPH kelompok padi-padian + umbi- umbian + pangan hewani + minyak dan lemak + buah/biji berminyak + kacang-kacangan + gula + sayur dan buah + skor PPH kelompok lain-lain.

\section{HASIL DAN PEMBAHASAN}

\section{Ketahanan Pangan Rumah Tangga}

Ketahanan pangan rumah tangga merupakan kondisi terpenuhinya kebutuhan konsumsi pangan dalam suatu rumah tangga yang tercermin dari tersedianya pangan yang cukup, aman, bergizi, berimbang, serta beragam. Tingkat ketahanan pangan 
Kezia et.al. Analisis Tingkat Ketahanan Pangan Rumah Tangga Berdasarkan

rumah tangga dapat diukur melalui klasifikasi silang dua indikator yaitu pangsa pengeluaran pangan dan kecukupan energi.

\section{Pangsa Pengeluaran Pangan}

Pengeluaran pangan adalah sebagian pengeluaran rumah tangga yang dibelanjakan untuk membeli kebutuhan konsumsi rumah tangga. Pangsa pengeluaran pangan merupakan jumlah pengeluaran yang dialokasikan untuk belanja pangan yang dibandingkan dengan total pengeluaran rumah tangga. Berikut merupakan data pengeluaran rumah tangga di Desa Karangtengah yang tersaji pada Tabel 3.

Tabel 3. Pengeluaran Rumah Tangga di Desa Karangtengah Tahun 2017

\begin{tabular}{lrr}
\multicolumn{1}{c}{ Variabel } & Rata-rata (Rp/bulan) & Persentase (\%) \\
\hline Pengeluaran Pangan & $934.659,09$ & 62,05 \\
Pengeluaran Non Pangan & $571.590,91$ & 37,95 \\
\hline Jumlah & 1.506 .250 & 100 \\
\hline
\end{tabular}

Sumber: Analisis Data Primer, 2019

Pada tabel 3 dapat diketahui bahwa rata-rata pengeluaran pangan rumah tangga di Desa Karangtengah adalah Rp 934.659,09 dengan persentase sebesar 62,05\% dan rata-rata pengeluaran non pangan sebesar Rp 571.590,91 dengan persentase sebesar 37,95\%. Menunjukkan bahwa sebagian besar rumah tangga Di Desa Karangtengah mengalokasikan pendapatannya untuk membeli kebutuhan pangan, hal tersebut menyebabkan pangsa pengeluaran rumah tangga Desa Karangtengah tinggi.

\section{Kecukupan Energi}

Kecukupan energi merupakan persentase antara jumlah konsumsi energi rumah tangga dengan jumlah angka kecukupan energi yang dianjurkan. Besarnya AKE berbeda-beda untuk setiap individu karena AKE ditentukan berdasarkan umur dan jenis kelamin. Konsumsi pangan rumah tangga didapat dari menggunakan metode food recall 24 jam yaitu metode pencatatan konsumsi pangan rumah tangga dalam kurun waktu 24 jam dengan pedoman Daftar Komposisi Bahan Makanan (DKBM). Konsumsi energi rumah tangga adalah jumlah energi pangan yang dikonsumsi per hari yang dinyatakan dalam $\mathrm{kkal} / \mathrm{hari}$. 
Jurnal Dinamika Sosisal Ekonomi, 21 (2) : 122-136

Tabel 4. Kecukupan Energi Rumah Tangga di Desa Karangtengah Tahun 2017

\begin{tabular}{lr}
\multicolumn{1}{c}{ Variabel } & Rata-rata \\
\hline Jumlah Konsumsi Energi Riil (kkal/hari) & $6.824,7$ \\
Jumlah Kecukupan Energi Yang Dianjurkan (kkal/hari) & $7.240,2$ \\
Kecukupan Energi (\%) & 94,26 \\
\hline
\end{tabular}

Sumber : Analisis Data Primer, 2019

Berdasarkan Tabel 4 dapat diketahui bahwa rata-rata konsumsi energi riil rumah tangga di Desa Karangtengah adalah sebesar 6.824,7 kkal/hari sedangkan kecukupan energi yang dianjurkan adalah sebesar 7.240,2 kkal/hari., diperoleh kecukupan energi sebesar 94,26\% yang menunjukkan bahwa konsumsi energi dalam katergori cukup.

Berdasarkan klasifikasi silang pangsa pengeluaran pangan dan kecukupan energi kemudian dapat diketahui tingkat ketahanan pangan rumah tangga Desa Karangtengah yang tersaji pada tabel 5.

Tabel 5. Tingkat Ketahanan Pangan Rumah Tangga di Desa Karangtengah Tahun 2017

\begin{tabular}{lrl}
\hline \multicolumn{1}{c}{ Indikator Ketahanan Pangan } & Rata-Rata $(\%)$ & \multicolumn{1}{c}{ Keterangan } \\
\hline Pangsa Pengeluaran Pangan & 62,05 & \multirow{2}{*}{ Rentan Pangan } \\
Kecukupan Energi & 94,26 & \\
\hline
\end{tabular}

Sumber: Analisis Data Primer 2019

Berdasarkan Tabel 5 rata-rata pangsa pengeluaran pangan rumah tangga Desa Karangtengah adalah sebesar 62,05\%, nilai ini lebih besar dari 60\% sehingga pangsa pengeluaran pangan rumah tangga Desa Karangtengah termasuk tinggi. Untuk ratarata konsumsi energi rumah tangga Desa Karangtengah adalah sebesar 94,26\%, nilai ini lebih besar dari 80\% sehingga konsumsi energi rumah tangga Desa Karangtengah adalah cukup. Apabila pangsa pengeluaran tinggi dan konsumsi energi adalah cukup maka tingkat ketahanan pangan rumah tangga Desa Karangtengah adalah rentan pangan. Untuk sebaran kategori ketahanan pangan rumah tangga Desa Karangtengah tersaji pada tabel 6 berikut: 
Kezia et.al. Analisis Tingkat Ketahanan Pangan Rumah Tangga Berdasarkan

Tabel 6. Sebaran Ketahanan Pangan Rumah Tangga Desa Karangtengah Tahun 2017

\begin{tabular}{|c|c|c|c|c|}
\hline Kategori Ketahanan Pangan & $\begin{array}{l}\text { Pangsa } \\
\text { Pengeluaran } \\
\text { Pangan } \\
(\%) \\
\end{array}$ & $\begin{array}{l}\text { Kecukupan } \\
\text { Energi } \\
(\%)\end{array}$ & $\begin{array}{l}\text { Jumlah } \\
\text { Rumah } \\
\text { Tangga }\end{array}$ & $\begin{array}{l}\text { Persentase } \\
\quad(\%)\end{array}$ \\
\hline $\begin{array}{ll}\text { Tahan Pangan, jika } & \text { pangsa } \\
\text { pengeluaran pangan } & <60 \% \text {, } \\
\text { konsumsi energi cukup } & (>80 \% \\
\text { kecukupan energi) } & \end{array}$ & 48,7 & 98,1 & 16 & 36,4 \\
\hline $\begin{array}{ll}\text { Rentan Pangan, jika } & \text { pangsa } \\
\text { pengeluaran pangan } & \geq 60 \% \text {, } \\
\text { konsumsi energi cukup } & (>80 \% \\
\text { kecukupan energi) } & \end{array}$ & 76,6 & 101,4 & 19 & 43,2 \\
\hline $\begin{array}{l}\text { Kurang Pangan, jika pangsa } \\
\text { pengeluaran pangan }<60 \% \text {, } \\
\text { konsumsi energi kurang }(\leq 80 \% \\
\text { kecukupan energi) }\end{array}$ & 47 & 65,6 & 2 & 4,5 \\
\hline $\begin{array}{ll}\text { Rawan Pangan, jika pangsa } & \text { pan } \\
\text { pengeluaran pangan } \geq 60 \%, & \\
\text { konsumsi energi kurang } & (\leq 80 \% \\
\text { kecukupan energi) }\end{array}$ & 76,4 & 76,1 & 7 & 15,9 \\
\hline Jumlah & & & 44 & 100 \\
\hline
\end{tabular}

Sumber : Analisis Data Primer, 2019

Pada tabel 6 dapat diketahui bahwa rumah tangga rentan pangan memiliki jumlah terbanyak yaitu 19 rumah tangga dengan persentase sebesar 43,2\%. Kondisi rentan pangan dapat terjadi karena adanya berbagai macam permasalahan seperti rendahnya pendapatan yang diperoleh maupun distribusi pangan yang kurang merata. Kecukupan energi rumah tangga dikatakan cukup dikarenakan rumah tangga mengkonsumsi jenis pangan sumber karbohidrat tinggi seperti beras. Selain itu rumah tangga juga memperoleh bahan pangan tersebut dengan harga yang murah, sehingga kecukupan energi dapat diperoleh.

\section{Diversifikasi Konsumsi Pangan Rumah Tangga}

Menurut Martianto (1992) dalam penelitian Ariani dan Ashari (2003), menyatakan dimensi diversifikasi konsumsi pangan tidak hanya terbatas pada konsumsi pangan pokok melainkan juga pada pangan pendampingnya. Sementara itu Tampubolon (1998) dalam Suyastiri (2008), menyatakan bahwa diversifikasi bahan pangan merupakan suatu proses pemilihan pangan yang tidak tergantung pada satu 
Jurnal Dinamika Sosisal Ekonomi, 21 (2) : 122-136

jenis pangan saja tetapi lebih terhadap berbagai bahan pangan mulai dari aspek produksi, aspek pengolahan, aspek distribusi hingga aspek konsumsi pangan pada tingkat rumah tangga. Alasan perlunya diversifikasi pangan untuk pencapaian pangan yang beragam,antara lain adalah: i) mengonsumsi pangan yang beragam merupakan alternatif terbaik untuk pengembangan sumber daya manusia yang berkualitas; ii) meningkatkan optimalisasi pemanfaatan sumber daya pertanian dan kehutanan; iii) memproduksi pangan yang beragam mengurangi ketergantungan kepada pangan impor; dan iv) mewujudkan ketahanan pangan yang merupakan kewajiban bersama pemerintah dan masyarakat. (Widowati dan Damardjati 2001) dalam (Elizabeth, 2011).

Diversifikasi konsumsi pangan dapat diukur melalui pendekatan skor PPH. Pola Pangan Harapan (PPH) adalah susunan beragam bahan makanan atau kelompok bahan makanan yang didasarkan pada sumbangan energi, baik secara absolut maupun relatif terhadap total energi, yang mampu memenuhi kebutuhan konsumsi pangan penduduk baik kuantitas, kualitas maupun keragaman. PPH merupakan instrumen sederhana untuk menilai mutu gizi konsumsi pangan kelompok baik jumlah maupun komposisi pangan menurut jenis pangan yang dinyatakan dalam skor. PPH juga sebagai instrumen untuk mengevaluasi pola konsumsi pangan masyarakat dan sekaligus sebagai bahan untuk merencanakan kebutuhan pangan tingkat regional dan nasional (Widodo et. al, 2017). Semakin tinggi skor PPH maka semakin beragam pangan yang dikonsumsi. Berdasarkan hasil perkalian antara proporsi energi dari masing-masing kelompok pangan dengan masing-masing pembobotnya maka diperoleh skor PPH di Desa Karangtengah, Kecamatan Sampang, Kabupaten Cilacap, Provinsi Jawa Tengah yang tersaji pada Tabel 7 berikut : 
Kezia et.al. Analisis Tingkat Ketahanan Pangan Rumah Tangga Berdasarkan

Tabel 7. Skor Pola Pangan Harapan Konsumsi Desa Karangtengah Tahun 2017

\begin{tabular}{|c|c|c|c|c|c|c|c|c|}
\hline \multirow[b]{2}{*}{ Kelompok Pangan } & \multicolumn{8}{|c|}{ Perhitungan Skor Pola Pangan Harapan (PPH) } \\
\hline & Kalori & $\%$ & $\begin{array}{c}\% \\
\text { AKE }\end{array}$ & Bobot & $\begin{array}{l}\text { Skor } \\
\text { Aktual }\end{array}$ & $\begin{array}{l}\text { Skor } \\
\text { AKE }\end{array}$ & $\begin{array}{l}\text { Skor } \\
\text { Maks }\end{array}$ & $\begin{array}{l}\text { Skor } \\
\text { PPH }\end{array}$ \\
\hline Padi - padian & 1094,5 & 51.8 & 50.9 & 0,5 & 25.9 & 25.5 & 25,0 & 25.0 \\
\hline Umbi-umbian & 45,6 & 2.2 & 2.1 & 0,5 & 1.1 & 1.1 & 2,5 & 1.1 \\
\hline Pangan Hewani & 269,4 & 12.8 & 12.5 & 2,0 & 25.5 & 25.1 & 24,0 & 24.0 \\
\hline Minyak dan Lemak & 212,5 & 10.1 & 9.9 & 0,5 & 5.0 & 4.9 & 5,0 & 4.9 \\
\hline Buah/Biji Berminyak & 59,8 & 2.8 & 2.8 & 0,5 & 1.4 & 1.4 & 1,0 & 1.0 \\
\hline Kacang-kacangan & 260,8 & 12.3 & 12.1 & 2,0 & 24.7 & 24.3 & 10,0 & 10.0 \\
\hline Gula & 43,2 & 2.0 & 2.0 & 0,5 & 1.0 & 1.0 & 2,5 & 1.0 \\
\hline Sayur dan Buah & 97,1 & 4.6 & 4.5 & 5,0 & 23.0 & 22.6 & 30,0 & 22.6 \\
\hline Lain - lain & 28,9 & 1.4 & 1.3 & 0,0 & 0.0 & 0.0 & 0,0 & 0.0 \\
\hline Jumlah & 2111,8 & 100,0 & 98,2 & 11,5 & 107,7 & 105,8 & 100,0 & 89,6 \\
\hline
\end{tabular}

Sumber : Analisis Data Primer, 2019

Berdasarkan Tabel 7. skor PPH di Desa Karangtengah pada tahun 2017 adalah sebesar 89,6 nilai ini belum memenuhi skor ideal PPH yaitu 100. dapat dilihat bahwa kelompok pangan yang menyumbang energi paling besar adalah kelompok pangan padi-padian yaitu sebesar 1094,5 kkal/kapita/hari atau sebesar 51,8\%. Sedangkan kelompok pangan yang menyumbang energi paling kecil adalah kelompok sayur/buah. Untuk konsumsi sayur dan buah dapat dikatakan masih jauh dari skor ideal PPH hal ini disebabkan karena masih saja terdapat rumah tangga yang kurang memperhatikan pentingnya kandungan gizi dari sayur dan buah. Biasanya rumah tangga yang berpendapatan minim akan lebih memilih konsumsi beras dan lauk seadanya seperti tempe goreng untuk mencukupi kebutuhan konsumsinya. Sehingga angka konsumsi sayur dan buah rumah tangga di Desa Karangtengah masih minim yakni 22,6 dari 30.

\section{KESIMPULAN DAN SARAN}

\section{Kesimpulan}

Tingkat ketahanan pangan rumah tangga di Kecamatan Sampang berdasarkan klasifikasi silang pangsa pengeluaran pangan dan konsumsi energi termasuk kedalam kategori rentan pangan dimana pangsa pengeluaran pangan sebesar 62,05\% dan 
Jurnal Dinamika Sosisal Ekonomi, 21 (2) : 122-136

kecukupan energi sebesar 94,26\%. Untuk tingkat diversikasi konsumsi pangan di Kecamatan Sampang berdasarkan perhitungan skor PPH adalah sebesar 89,6.

\section{Saran}

Untuk meningkatkan pendapatan masyarakat terutama masyarakat yang bekerja sebagai buruh tani sebaiknya dilaksanakan pelatihan mengolah bahan makanan yang memanfaatkan pangan lokal berupa umbi-umbian. Sehingga rumah tangga memiliki pendapatan tambahan dari mengolah pangan lokal. Untuk meningkatkan konsumsi sayur dan buah sebaiknya dilakukan pelatihan budidaya tanaman pangan (sayur) yang memanfaatkan pekarangan rumah dengan melibatkan tidak hanya pada kelompok wanita tani namun kepada para ibu rumah tangga. Dengan melibatkan para ibu rumah tangga diharapkan mampu menekan pengeluaran pangan terutama pengeluaran untuk belanja sayur.

\section{DAFTAR PUSTAKA}

Anggraini, Meilia; Wan Abbas Zakaria; Fembriarti Erry Prasmatiwi. (2014). Ketahanan Pangan Rumah Tangga Petani Kopi di Kabupaten Lampung Barat. Jurnal IIA. Lampung. Universitas Lampung, 2(2) 124-132.

Arida, Agustina; Sofyan; Keumala Fadhiela. (2015). Analisis Ketahanan Pangan Rumah Tangga Berdasarkan Proporsi Pengeluaran Pangan dan Konsumsi Energi Studi Kasus Pada Rumah Tangga Petani Peserta Program Desa Mandiri Pangan di Kecamatan Indrapuri Kabupaten Aceh Besar. Jurnal Agrisep. Banda Aceh. Universitas Syiah Kuala, 16(1), 20-34.

Ariani, Mewa dan Ashari. (2003). Arah, Kendala dan Pentingnya Diversifikasi Pangan di Indonesia. Jurnal Forum Penelitian Agro Ekonomi. Bogor. Pusat Penelitian dan Pengembangan Sosial Ekonomi Pertanian, 21(2), 99-112.

Badan Ketahanan Pangan. (2015). Panduan Penghitungan Pola Pangan Harapan (PPH). Badan Ketahanan Pangan Kementerian Pertanian 2015.

Badan Pusat Statistik Kabupaten Cilacap. (2018). Kecamatan Sampang Dalam Angka Tahun 2018. Badan Pusat Statistik Kabupaten Cilacap 2017.

Dewan Ketahan Pangan. (2006). Kebijakan Umum Ketahanan Pangan 2006 - 2009. Jurnal Gizi dan Pangan, 1(1), 57-63.

Dirhamsyah, Tedy; Jangkung Handoyo Mulyo; Dwidjono Hadi Darwanto; Slamet Hartono. (2016). Ketahanan Pangan (Kemandirian Pangan dan Kesejahteraan Masyarakat Daerah Rawan Pangan di Jawa). Yogyakarta: Plantaxia. 
Kezia et.al. Analisis Tingkat Ketahanan Pangan Rumah Tangga Berdasarkan

Elizabeth, Roosganda. (2011). Strategi Pencapaian Diversifikasi Dan Kemandirian Pangan: Antara Harapan dan Kenyataan. Jurnal Iptek Tanaman Pangan. Bogor. Pusat Analisis Sosial Ekonomi dan Kebijakan Pertanian, 6(2), 230-242.

Menteri Kesehatan. (2013). Peraturan Menteri Kesehatan No. 75 Tahun 2013 tentang Penetapan WNPG X Tahun 2012. Lembaran Negara RI Tahun 2013, No. 75. Jakarta: Sekretariat Negara.

Nazir. (2014). Metode Penelitian Cetakan ke-9. Bogor: Ghalia Indonesia.

Purwaningsih, Yuniastiti. (2008). Ketahanan Pangan: Situasi, Permasalahan, Kebijakan, dan Pemberdayaan Masyarakat. Jurnal Ekonomi Pembangunan. Surakarta. Universitas Sebelas Maret, 9(1), 1-27.

Sugiyono. (2016). Metode Penelitian Kombinasi (Mixed Methods) Cetakan ke-8. Bandung: Alfabeta.

Suharyanto. (2015). Karakteristik Tingkat Ketahanan Pangan Rumah Tangga Petani Berbasis Agroekosistem Lahan Sawah Irigasi Di Provinsi Bali. Jurnal SEPA. Bali. Balai Pengkajian Teknologi Pertanian Bali, 11(2), 191-199.

Suyastiri, Ni Made. (2008). Diversifikasi Konsumsi Pangan Pokok Berbasis Potensi Lokal Dalam Mewujudkan Ketahanan Pangan Rumah Tangga Pedesaan di Kecamtan Semin Kabupaten Gunung Kidul. Jurnal Ekonomi Pembangunan. Yogyakarta. Fakultas Pertanian UPN "Veteran" Yogyakarta, 13(3), 51-60.

Widodo, Yekti; Sandjana; Fitrah Emawati. (2017). Skor Pola Pangan Harapan dan Hubungannya Dengan Status Gizi Anak Usia 0,5 - 2 Tahun di Indonesia. Jurnal Penelitian Gizi dan Makanan. Jakarta. Pusat Penelitian dan Pengembangan Upaya Kesehatan Masyarakat, 40(2), 63-75. 